\title{
Natural variation of H3K27me3 distribution between two Arabidopsis accessions and its association with flanking transposable elements
}

\author{
Xue Dong ${ }^{1,3 \dagger}$, Julia Reimer ${ }^{1 \dagger}$, Ulrike Göbel ${ }^{1}$, Julia Engelhorn ${ }^{1}$, Fei $\mathrm{He}^{2}$, Heiko Schoof $^{3^{*}}$ and Franziska Turck ${ }^{1 *}$
}

\begin{abstract}
Background: Histone H3 lysine 27 tri-methylation and lysine 9 di-methylation are independent repressive chromatin modifications in Arabidopsis thaliana. H3K27me3 is established and maintained by Polycomb repressive complexes whereas H3K9me2 is catalyzed by SUVH histone methyltransferases. Both modifications can spread to flanking regions after initialization and were shown to be mutually exclusive in Arabidopsis.

Results: We analyzed the extent of natural variation of H3K27me3 in the two accessions Landsberg erecta (Ler) and Columbia (Col) and their F1 hybrids. The majority of H3K27me3 target genes in Col were unchanged in Ler and F1 hybrids. A small number of Ler-specific targets were detected and confirmed. Consistent with a cis-regulatory mechanism for establishing H3K27me3, differential targets showed allele-specific H3K27me3 in hybrids. Five Lerspecific targets showed the active mark H3K4me3 in Col and for this group, differential H3K27me3 enrichment accorded to expression variation. On the other hand, the majority of Ler-specific targets were not expressed in Col, Ler or 17 other accessions. Instead of H3K27me3, the antagonistic mark H3K9me2 and other heterochromatic features were observed at these loci in Col. These loci were frequently flanked by transposable elements, which were often missing in the Ler genome assembly.

Conclusion: There is little variation in H3K27me3 occupancy within the species, although H3K27me3 targets were previously shown as overrepresented among differentially expressed genes. The existing variation in H3K27me3 seems mostly explained by flanking polymorphic transposable elements. These could nucleate heterochromatin, which then spreads into neighboring H3K27me3 genes, thus converting them to H3K9me2 targets.
\end{abstract}

\section{Background}

Eukaryotic nuclear DNA is organized in a higher order chromatin structure that enables the required dense packaging, but also limits access to nuclear DNA. To overcome the chromatin barrier, chromatin associated complexes enable local and temporal opening of chromatin so that crucial processes such as transcription, replication and DNA repair can take place. In contrast, mechanisms that reinforce chromatin compaction have been integrated in pathways that confer stable gene repression. In particular, two evolutionarily conserved

\footnotetext{
* Correspondence: schoof@uni-bonn.de; turck@mpipz.mpg.de

+ Contributed equally

${ }^{1}$ Max Planck Institute for Plant Breeding Research, Carl von Linne Weg 10, 50829 Köln, Germany

${ }^{3}$ Current address: University of Bonn, Institute of Crop Science and Resource Conservation, Crop Bioinformatics, Katzenburgweg 2, 53115 Bonn, Germany Full list of author information is available at the end of the article
}

pathways of chromatin-mediated gene repression have been described [1-3]. The SU(VAR)3-9 pathway and the related SUVH pathway in plants effectively silence target loci due to heterochromatin formation $[4,5]$. In plants, gene silencing is in general stably inherited throughout meiosis [6]. Main targets of the SUVH pathway are transposable elements (TEs) and derived repeats. In contrast, the Polycomb group (PcG) pathway causes persistent but reversible repression of euchromatic genes that can be inherited throughout mitosis but is reset during meiosis. The PcG pathway plays a crucial role in the regulation of genes that have important developmental functions [7].

Central to both pathways are SET domain histone methyltransferases (HMTs) that specifically modify lysine residues at either position 9 or 27 of histone H3, both sites being embedded in evolutionarily conserved 
ARKS motifs in the amino-terminal tail of $\mathrm{H} 3$ [8]. Histone tails and their modifications do not contribute to nucleosome structure or stability, but serve as recognition sites for chromatin-associated complexes that are required for chromatin compaction and gene repression [9]. For both repressive pathways, a mechanism designated as 'spreading' has been described. In the spreading model, the HMT complexes are first recruited to a nucleation region by a specific signal, which could be a DNA-binding protein or non-coding RNA. The histone modification then spreads from this nucleation site to neighboring regions due to an auto-catalytic process [10]. The amplification is dependent on the direct or indirect recruitment of the HMT complex by its own target modification. Such an auto-catalytic loop has been described for mammalian SU(VAR)3-9, which is known to interact physically with HETEROCHROMATIN PROTEIN 1 (HP1) [4]. HP1 directly binds the H3K9me2 and H3K9me3 modification through its chromodomain [4]. In the PcG pathway, it was shown that an accessory component of the HMT containing complex interacts with the H3K27me3 mark [11,12].

In Arabidopsis, the production of small interfering RNAs (siRNAs) of 23 to 24 nucleotides in length leads to the recruitment of several HMTs of the SUVH-type to complementary sites, resulting in di-methylation of lysine 9 of H3 [13]. These siRNAs are generated from doublestranded RNA transcripts and primarily target TEs or related repetitive DNA. The chromo-domain containing DNA-methylase Chromo-methylase 3 (CMT3) is recruited by $\mathrm{H} 3 \mathrm{~K} 9 \mathrm{me} 2$ and this contributes to an increase in cytosine DNA-methylation at the sites marked by H3K9me2 [14]. However, DNA-methylation can also be recruited to target sites by siRNAs independently of H3K9me 2 and may in fact result in increased recruitment of H3K9me2, both mechanisms contributing to the spreading of H3K9me2 domains in plants [15]. In animals, boundary sequences that carry H2Bub1 have been shown to limit spreading of heterochromatin into neighboring regions [16].

The SET domain component of Polycomb repressive complex (PRC) 2 tri-methylates lysine 27 of $\mathrm{H} 3$ and this modification is recognized by PRC1. In contrast to H3K9me2, the H3K27me3 modification is not correlated with cytosine methylation in plants $[17,18]$. In plants, the chromodomain protein LIKE HETEROCHROMATIN PROTEIN 1 (LHP1) recognizes the H3K27me3 modification as part of a PRC1-like complex, although its closest animal homologs, the HP 1 family members, are an integral part of the SU(VAR)3-9 pathway. In plants and animals, PRC1 also comprises RING domain proteins that ubiquitinate lysine residues within the body of $\mathrm{H} 2 \mathrm{~A}$ $[19,20]$. In animal models, it has been shown that H2A ubiquitination is crucial for chromatin compaction and target gene repression [21]. Different modes of PRC2 recruitment to target sites have been reported and it is possible that several mechanisms act synergistically. In fruitflies, Polycomb response elements are regulatory regions that contain arrays of cis-elements involved in PRC2 recruitment [22]. In addition, intergenic non-coding RNAs such as the HOTAIR transcript have been implicated in PRC2 targeting [23]. Recently, the intron-encoded non-coding RNA COLDAIR was shown to specifically bind the plant PRC2 complex to stably repress a target gene [24].

Several genomic studies in Arabidopsis thaliana identified a large number of genes (about 15\% of all genes in the annotated genome of the Columbia ( $\mathrm{Col})$ accession) as marked with H3K27me3 [25-27]. H3K27me3-enriched regions often span large proportions of their target gene, but they rarely spread into neighboring annotated units [25,26]. Most H3K27me3-marked genes show low expression levels throughout development or are expressed in a highly tissue-specific manner [26].

Here, we address the question of to what extent H3K27me3 distribution varies between two accessions of Arabidopsis and point out genomic features that may explain this variation at a genetic and epigenetic level. We discovered that H3K27me3 targets specific to one accession are often repressed by other repressive marks such as H3K9me2 and DNA methylation in the reference accession. The insertion of TEs in the vicinity of accessionspecific H3K27me3 targets followed by heterochromatin spreading and invasion of $\mathrm{H} 3 \mathrm{~K} 27 \mathrm{me} 3$ domains seems to play a major role in creating the epigenetic variation. We could show that variation in H3K27me3 enrichment was inherited strictly in cis in F1 hybrids between both accessions.

\section{Results}

\section{Col and Ler have highly similar H3K27me3 profiles}

To uncover the natural variation of H3K27me3 distribution within the species $A$. thaliana, the genome-wide distribution of H3K27me3 in two accessions, Col and Ler, was profiled using chromatin immunoprecipitation (ChIP) followed by hybridization to whole-genome tiling microarrays (ChIP-chip). The original probes based on the TAIR6 Arabidopsis genome release were remapped to TAIR9 to ensure that unique, high quality probes were used to predict H3K27me3 targets in Col and Ler. A visual analysis of the Col and Ler H3K27me3 levels with GBrowse revealed that the majority of loci exhibited very similar H3K27me3 enrichment along chromosomes (Figure S1 in Additional file 1). Based on unique probes in Col after remapping, 6,370 and 6,344 H3K27me3 targets were identified in Col and Ler, respectively (Figure 1a; Additional file 2). This number of H3K27me3 targets in $\mathrm{Col}$ is consistent with previous studies carried out on Col seedlings by different 


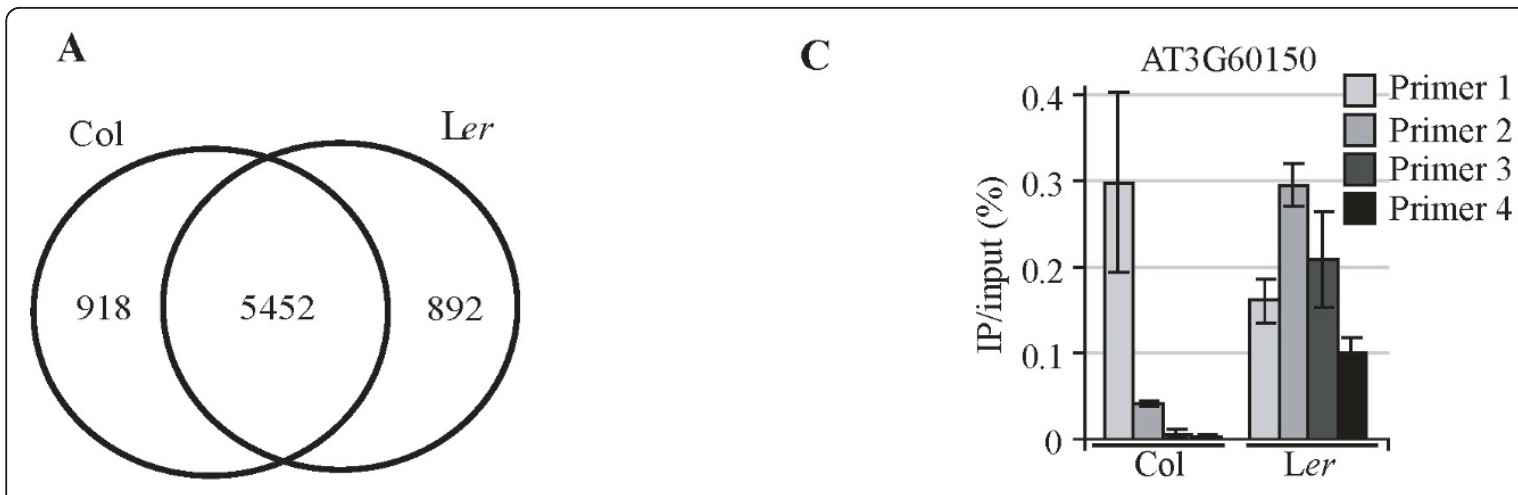

B

Chr3

Chr3:22217809..22227809

$22218 \mathrm{k} 22219 \mathrm{k} \quad 2220 \mathrm{k} \quad 2222 \mathrm{k} \quad 2222 \mathrm{k} \quad 2223 \mathrm{k} \quad 22224 \mathrm{k}$

Locus

AT3G60140 AT3G60150

H3K27me3 Col

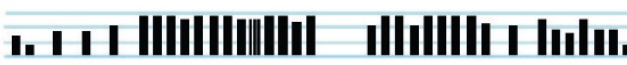

H3K27me3 Ler

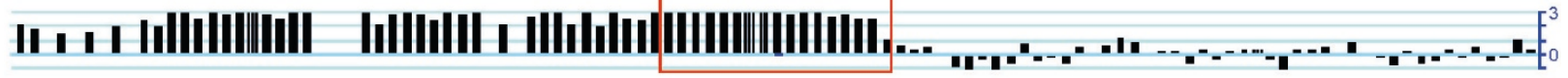

PCR fragments

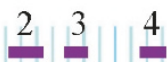

\section{Protein Coding Gene Models}

AT3G60140.1

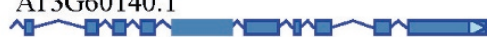

Figure 1 Identification and validation of Ler-specific H3K27me3 targets. (a) Venn diagram of H3K27me3 targets identified in Col and Ler. (b) GBrowse view of AT3G60150 as an example for a Ler-specific H3K27me3 target. The red frame indicates the location of AT3G60150 and the differential H3K27me3 signal in Col and Ler. (c) Validation of AT3G60150 by independent ChIP-PCR. ChIP-PCR fragment location is indicated in track 'PCR fragments' in (b). IP, immunoprecipitation.

laboratories using various experimental platforms [26-29]. There are 5,452 H3K27me3 targets shared between Col and Ler, indicating highly similar H3K27me3 profiles between the two accessions (Figure 1a).

\section{Differential H3K27me3-enriched genes are rare between Col and Ler}

The global comparison of targets between two accessions did not permit an evaluation of statistical significance and could indeed be fully explained by a false discovery rate inherent to genome-wide approaches. In addition, when using the same microarrays for two different Arabidopsis accessions, some amount of differential signals are to be expected due to sequence polymorphisms. The major sequence polymorphisms between Col and Ler include presence/absence polymorphisms, copy number differences and single nucleotide changes (SNPs). Presence/ absence polymorphisms lead to a signal being detectable in only one genome, which could be wrongly identified as a differentially methylated target. Copy number differences result in different cross-hybridization signals. SNPs lower the efficiency in hybridization and thus may result in a lower signal and false identification of differential targets.

To overcome these limitations, we tested each gene individually for differential signal. We used rank product statistics after calculating a median enrichment value over each gene body [30,31]. The analysis only included probes that mapped uniquely to both the Col genome and the published Ler assembly (see Materials and methods) [32]. To identify genes enriched for H3K27me3 only 
in Ler, a maximal number of two mismatches were permitted so that homologous genes with moderate sequence diversity in Ler were retained. In contrast, for the identification of Col-specific H3K27me3 targets, no mismatch $(n=0)$ was allowed during remapping, which means only probes with perfect, unique matches in both accessions were included. This excludes false positives due to SNPs in Ler that lead to a lower signal of nonperfectly matching probes. As a consequence of the stringent remapping, approximately $25 \%$ of the genes annotated in TAIR9 and $10 \%$ of the H3K27me3 target genes detected by genome-wide target prediction in both $\mathrm{Col}$ and Ler were removed from the potential target set due to a probe density that was too low to judge their methylation state in both accessions (Additional file 3). Setting a significance threshold for a proportion of false positives of $15 \%$ ( $\mathrm{pfp}=0.15$ ), we identified $32 \mathrm{Ler}$-specific and 11 Col-specific H3K27me3 targets (Table S3 in Additional file 1). Differential H3K27me3 occupancy in $\mathrm{Col}$ and Ler was confirmed by quantitative PCR (qPCR) for 14 of 15 randomly chosen Ler-specific H3K27me3 targets using independently prepared ChIP samples, confirming that the prediction is as reliable as expected at an observed false positive rate of 0.07 (Figure 1b,c; Figure S2A in Additional file 1). However, the Col-specific H3K27me3 targets showed inconsistent results between ChIP-chip and ChIP-PCR. This is most likely due to the difficulties associated with using a microarray designed for only one accession, Col. We therefore excluded Colspecific H3K27me3 targets from our further analysis (Figure S2B in Additional file 1).

\section{Ler-specific H3K27me3 targets can be clustered into two groups based on their expression patterns}

Previous studies showed that H3K27me3 target genes are lowly expressed in Arabidopsis, although a considerable number can reach high expression levels in specific tissues or conditions $[25,26]$. Two recent genome-wide comparisons of $\mathrm{H} 3 \mathrm{~K} 27 \mathrm{me} 3$ distribution in specific tissues revealed a tendency for locally reduced H3K 27 me3 levels in tissues where the corresponding target genes are expressed $[29,33]$. In particular, H3K27me3 target genes expressed exclusively in either floral organs, the shoot apex or seeds often play a regulatory role in development and show an overrepresentation of transcriptional regulators [26,34]. In contrast, the Gene Ontology annotation for Ler-specific H3K27me3 targets included no functions in development or transcriptional regulation (data not shown).

To further characterize the Ler-specific H3K27me3 targets, we analyzed their expression in Col, Ler and other accessions. Expression patterns in different developmental stages and tissues in $\mathrm{Col}$ were explored using Arabidopsis thaliana Tiling Array Express (At-TAX) expression data, which have been generated by whole genome tiling microarrays [35]. Based on this analysis, Ler-specific H3K27me3 targets clustered in two very distinct groups (Figure 2a). One group (termed Rep_Col) contained 26 genes and showed no expression in almost all included samples, despite the absence of the repressive mark of H3K27me3 in Col. A smaller group of five genes showed relatively high expression in almost all studied samples (termed Exp_Col).

We then further investigated the expression pattern of Ler-specific H3K27me3 targets in seedlings of 19 Arabidopsis accessions as determined by RNA-seq [36]. The 19 accessions had been selected to represent the diversity within the species; Col and Ler are relatively closely related within the group. Exp_Col and Rep_Col genes showed expression characteristics consistent with their class in seedlings of 19 Arabidopsis accessions (Figure 2b): four of five Exp_Col genes showed variable expression among accessions. The fifth gene, AT1G30835, a SADHU retroelement, was not analyzable in this dataset. However, natural variation in expression of SADHU TEs has been described earlier. AT1G30835 is highly expressed in Col and was considered to be silent in Ler [37]. Notably, the remaining four genes were at their lowest expression in Ler but only occasionally repressed among the other 18 accessions. All Rep_Col genes, except AT2G20910, showed constant repression in seedlings in all 19 accessions. AT2G20910, annotated as a pseudogene in Col, showed expression in seedlings of only two accessions in addition to Ler. Expression data from seedlings cannot capture a tissue- or stage-specific expression pattern that is often shown by H3K27me3 target genes [26]. To better explore the expression pattern of Ler-specific H3K27me3 targets at different stages and in different tissues, we directly measured the transcription level of nine Ler-specific H3K27me3 targets in Col and Ler. The nine targets included all five Exp_Col and four Rep_Col genes. Exp_Col genes showed a typical tissue or stage-restricted expression pattern commonly observed for $\mathrm{H} 3 \mathrm{~K} 27 \mathrm{me} 3$ targets (Figure 2c). The four Rep_Col genes, on the other hand, were constantly repressed in both accessions at all time points analyzed irrespective of the absence or presence of H3K27me3 (Figure 2c). In conclusion, the expression pattern of Ler-specific H3K27me3 targets in Ler and Col confirmed that these can be categorized into two groups, one generally more active in the absence of the repressive H3K27me3 modification and the other transcriptionally repressed despite the absence of H3K27me3.

\section{Ler-specific H3K27me3 targets are associated with distinct histone modifications in Col}

To evaluate how the expression pattern of Ler-specific H3K27me3 targets accords with other histone modifications, we investigated the signal profiles of several active 


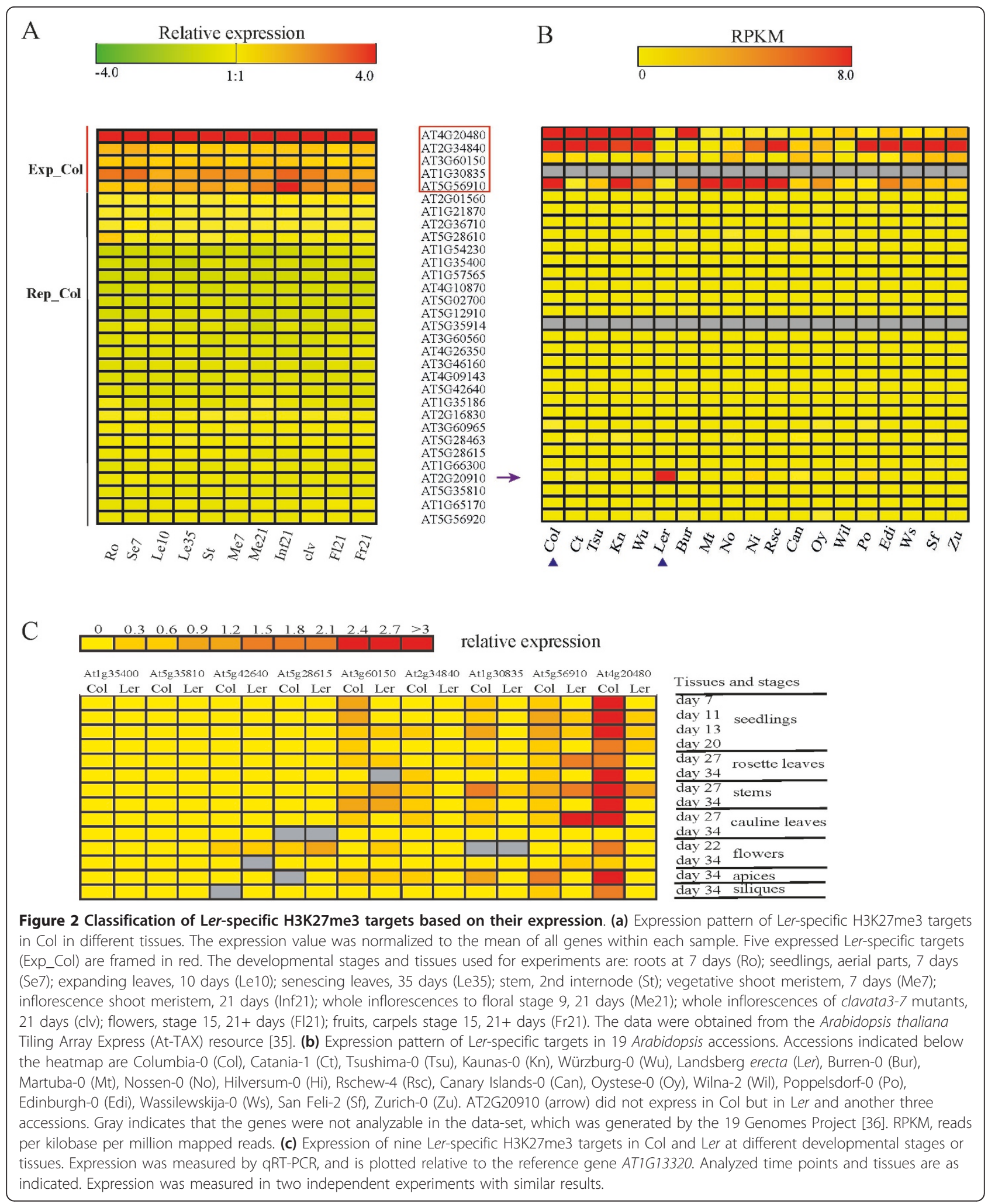


and repressive histone marks that have been mapped in Col seedlings. As expected, both Rep_Col and Exp_Col genes were depleted of $\mathrm{H} 3 \mathrm{~K} 27 \mathrm{me} 3$ in $\mathrm{Col}$ whereas targets in general are highly $\mathrm{H} 3 \mathrm{~K} 27 \mathrm{me}$-enriched, especially over the gene body (Figure 3a). Being consistent with their active expression in Col, Exp_Col genes were enriched for the active mark H3K4me3 (Figure 3b) [27]. In contrast, Rep_Col genes were depleted in this mark (Figure 3b). The H3K4me3 pattern of Rep_Col in Col was similar to that of H3K27me3 targets (Figure 3b). In contrast, in non-targets, the H3K4me3 enrichment peaked at the 5 end of the transcribed region as it did in the Exp_Col set.

H2A.Z has been implicated in multiple roles in divergent organisms $[38,39]$. It was proposed that the incorporation of H2A.Z could promote histone turnover and chromatin accessibility. In embryonic stem cells, H2A.Z is enriched at PcG target genes and necessary for lineage commitment [40]. In Arabidopsis, H2A.Z is preferentially enriched around the transcriptional start site and the 3' end of genes (Figure 3c) [41]. Unexpectedly, in Arabidopsis the mark also extended across larger regions into the gene bodies over H3K27me3 target genes. Exp_Col genes showed high H2A.Z signal at the transcriptional start site, thus behaving as most non-H3K27me3 genes. In contrast, Rep_Col were not labeled by H2A.Z in Col, thus representing a set distinct from both H3K27me3 target and non-target genes.

Besides H3K27me3, H3K9me2 and DNA methylation are associated with gene repression. In contrast to the euchromatic mark H3K27me3, these two marks are mainly located in constitutive heterochromatin [42,43]. To evaluate if these repressive histone modifications are associated with the Rep_Col set, the percentage of genes being marked by these repressive modifications was calculated from available data sets [42,43]. H3K9me2 frequently marked Rep_Col genes, both in gene bodies and their surrounding regions, while H3K27me3 targets, non-targets and Exp_Col showed much lower levels, especially within gene bodies (Figure 3d). We confirmed the change from H3K27me3 to H3K9me2 enrichment for a subset of Ler-specific H3K27me3 targets by ChIP-PCR (Figure S3 in Additional file 1). Consistent with the enrichment of H3K9me2, DNA methylation was also found highly enriched at Rep_Col but depleted at Exp_Col and H3K27me3 target genes (Figure 3e). H3K9me2 occurrence and in particular non-CG DNA methylation are highly correlated with siRNAs of 23 to 24 bp length [13]. Interestingly, the gene bodies of the Rep_Col set were devoid of these siRNAs as were the gene bodies of all other compared categories. However, Rep_Col genes were frequently flanked by siRNAs at their 5' and 3' ends, indicating that the heterochromatic status of Rep_Col genes may be explained by flanking genomic features (Figure 3f).

\section{Ler-specific H3K27me3 targets are often flanked by transposable elements in the Col genome}

TE-related sequences and their associated heterochromatic features are greatly enriched in pericentromeric regions where few actively transcribed genes can be found. To exclude the possibility that these genes were clustered within the pericentromeric regions, we mapped the chromosomal distribution of Ler-specific H3K27me3 targets and found them mostly distributed around the euchromatic chromosome arms. The location of Ler-specific H3K27me3 targets did not correlate with a general increase in TE or SNP density (Figure 4a). We therefore hypothesized that H3K9me2 at Ler-specific H3K27me3 targets in Col might be recruited by TEs present in dispersed heterochromatin found in the chromosome arms. Indeed, the percentage of Ler-specific H3K27me3 targets flanked by TEs in Col was significantly higher than that of non-H3K27me3 target controls (permutation test, $P<$ 0.01; Figure 4b). However, H3K27me3 targets in general were also more likely to be flanked by TEs than non-target genes (Figure 4b). Notably, the absence or presence of TEs did not distinguish the Rep_Col from the Exp_Col set as three genes of the Exp_Col set were neighbors of a heterochromatin-associated TE (Table 1). In total, 23 Ler-specific H3K27me3 targets were marked by H3K9me2 and 19 flanked by at least one annotated TE. Four genes are themselves annotated as TE genes (Figure 4c; Table S4 in Additional file 1). H3K9me2 targets are found significantly more frequently in the set of Ler-specific H3K27me3 targets than in the set of all non-H3K27me3 targets (hypergeometric test, $P=1 \mathrm{e}-07$ ).

\section{TE insertions in Col and local genome rearrangements were found at a majority of $\mathrm{H} 3 \mathrm{~K} 27 \mathrm{me} 3$ variant loci}

The overrepresentation of TEs as neighbors of H3K27me3 target genes could create a higher imminent risk of H3K27me3 genes to be taken over by heterochromatin spreading. Such heterochromatic invasion could be stochastic and lead to accession-specific variation or could be explained by a variant propensity of specific TE families to spread in one accession but not the other. Alternatively, absence/presence polymorphisms of TEs could explain the epigenetic variation. To distinguish between these possibilities, we evaluated whether TEs that neighbor Ler-specific H3K27me3 targets in Col are also present in the Ler genome. A whole genome alignment between the $\mathrm{Col}$ reference genome and the Ler draft genome [32] was carried out to extract sequences of Ler-specific H3K27me3 targets and their surrounding regions $(5,000 \mathrm{bp}$ up-/downstream of each gene body) in the two genomes. In 11 out of 23 cases, TEs flanking Ler-specific H3K27me3 targets were missing in the Ler draft genome (Table 1). An example of a clean absence/presence polymorphism is AT5G35820, which is missing in Ler while the flanking neighbors AT5G35810 


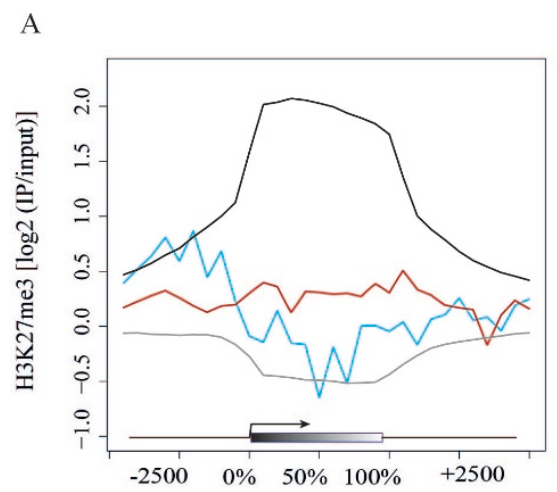

B

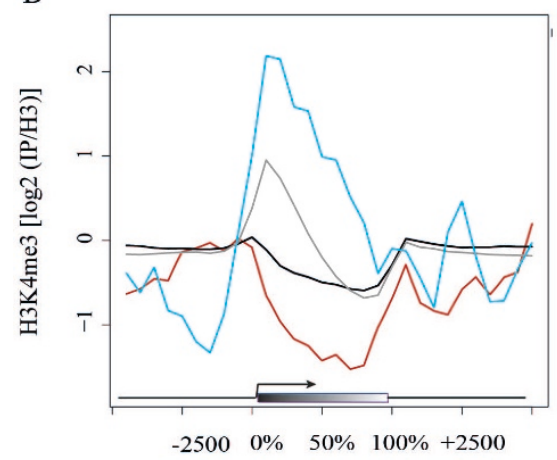

$\mathrm{C}$

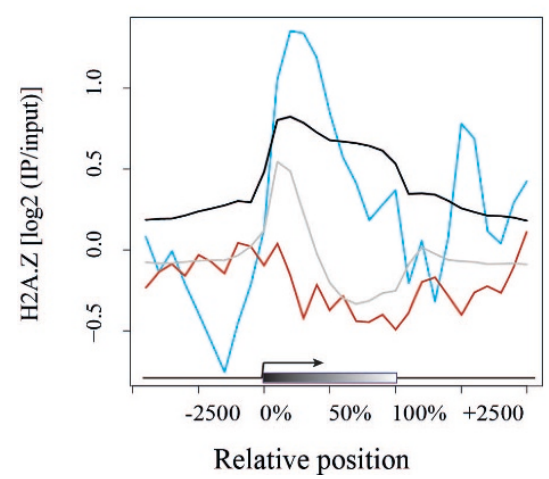

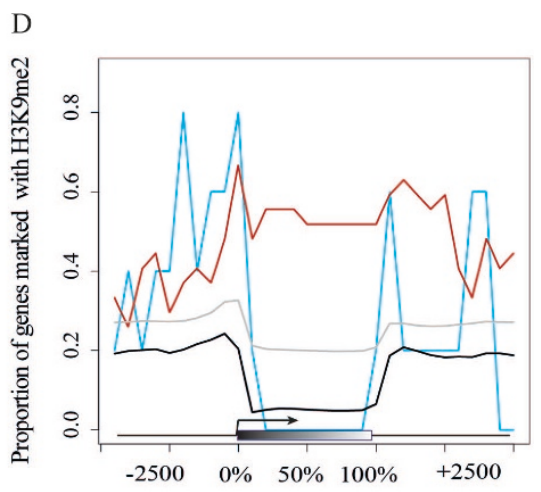

$\mathrm{E}$

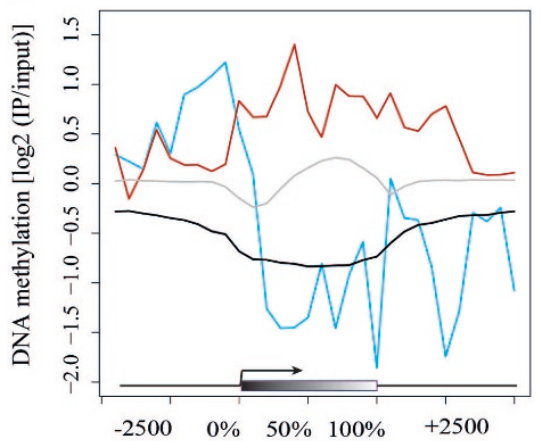

$\mathrm{F}$

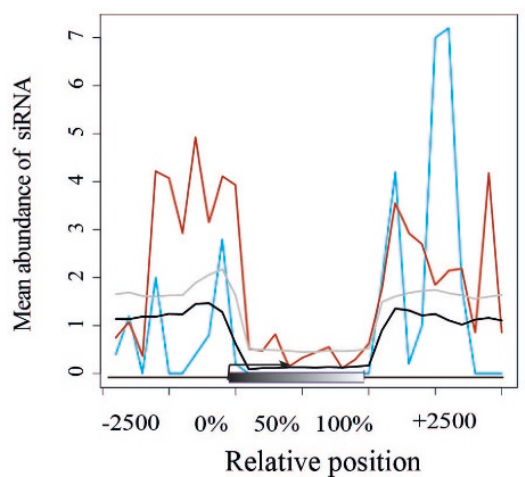

Figure 3 Association of Ler-specific H3K27me3 targets with chromatin modifications. The degree of overlap with histone-modification positive regions was plotted for 10\% length intervals along the gene body and for 500 bp sequence intervals for the 5-kb regions up- and downstream for Rep_Col (red), Exp_Col (blue), common H3K27me3 target (black) and non-H3K27me3 target genes (gray). The x-axis shows the relative position (gene body indicated by gray box), the $y$-axis represents mean signal of the respective mark (for $(a, b, c, e)$ ), proportion of genes overlapping with the mark (d) or normalized mean feature counts (f). (a) Enrichment of H3K27me3, (b) H3K4me3 [27], (c) H2A.Z [41], (d) H3K9me2 [42], (e) DNA methylation [42] and (f) association with 24-nucleotide siRNAs [62] of Rep_Col, Exp_Col, H3K27me3 targets and non-targets.

(Ler-specific H3K27me3 target) and AT5G35830 (common H3K27me3 target) are highly similar between the two accessions (Figure 5a; Figure S4 in Additional file 1). For intact polymorphic TEs, it is possible to distinguish between insertion and excision events by analyzing the target site signature. We selected five polymorphic, apparently intact TEs for verification by PCR amplification and Sanger sequencing (Table 1). The data indicate that the Ler draft genome correctly identified the polymorphisms, which were in four cases more likely explained by a TE insertion in Col as opposed to an excision in Ler based on the detection of target site duplications in Col but not Ler. Interestingly, in two cases polymorphic TEs were linked to Exp_Col genes, indicating that the insertion of a TE was not sufficient to predict heterochromatic invasion.

The low number of Ler-specifc H3K27me3 genes precludes a significant statement about whether certain transposons are more likely to cause heterochromatic 
A

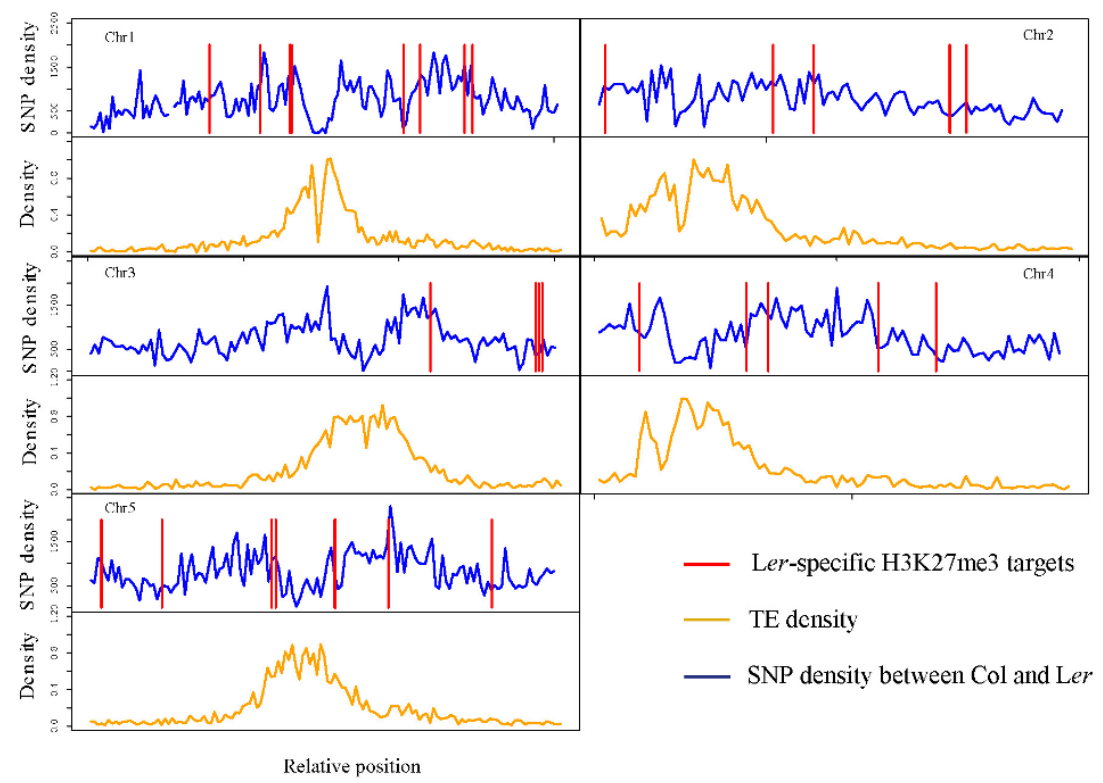

$\mathrm{B}$

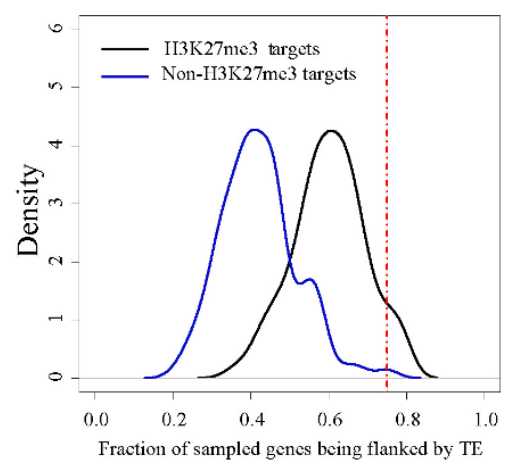

$\mathrm{C}$

Ler-specific H3K27me3 genes (32)



Flanked by TE (23) Targeted by H3K9me2 (19)

Figure 4 Association of Ler-specific H3K27me3 targets with TEs and H3K9me2. (a) The distributions of Ler-specific H3K27me3 targets relative to heterochromatic regions in chromosomes of Col. The red lines indicate the locations of Ler-specific H3K27me3 targets; the blue lines indicate the SNP density between Col and Ler; the brown lines indicate the density of TEs. (b) Density plot of fraction of genes flanked by a TE in a permutation test (sample size $=28,200$ drawings). The density is shown on the $y$-axis; the fraction of genes flanked by a TE for each sampling is shown on the $\mathrm{x}$-axis. Non-H3K27me3 targets are indicated in blue, H3K27me3 targets in black. The dashed red line shows the fraction of 28 non-TE Ler-specific H3K27me3 targets flanked by TEs in Col. (c) Association of Ler-specific H3K27me3 targets with flanking TEs and the H3K9me2 mark. 19 Ler-specific targets are H3K9me2 in Col, of which 15 are flanked by a TE. The number in brackets shows the number of annotated TE genes within the respective category.

invasion. We therefore investigated genome-wide if certain polymorphic TEs were more likely to spread heterochromatin into neighboring protein coding genes. To do this, the polymorphic regions identified by Schneeberger et al.[32] were annotated for the presence of TEs in Col. Compared to all TE classes, LTR/Copia and LINE elements were most polymorphic between Col and Ler, considering presence in $\mathrm{Col}$ and absence in Ler (Figure 5b,c). For 968 inserted TEs, 965 flanking protein-coding genes without $\mathrm{TE}$ insertion directly within the gene were identified in Col. Among these 965 protein-coding genes, 89 were found to be labeled with H3K9me2 [42]. Thus, protein-coding genes flanking Col-specific TEs are more frequently marked by H3K9me2 than expected on the basis of targets in the whole genome (hypergeometric test, $P=2$ e-11). Compared with the distribution of all inserted TEs, the LTR/ Copia family of retrotransposons was overrepresented among all TEs flanking H3K9me2-targeted protein coding genes (hypergeometric test, $P<0.005$ ). Indeed, all Ler-specific H3K27me3 genes that had acquired an LTR/Copia neighbor belonged to the heterochromatic 
Table 1 Ler-specific H3K27me3 targets adjacent to TEs polymorphic between Col and Ler

\begin{tabular}{|c|c|c|c|c|c|c|c|}
\hline Left_TE & $\begin{array}{l}\text { Ler-specifc } \\
\text { H3K27me3 }\end{array}$ & Group & Right_TE & TE family & $\begin{array}{l}\text { PCR size in } \\
\text { Col }\end{array}$ & $\begin{array}{l}\text { PCR size in } \\
\text { Ler }\end{array}$ & $\begin{array}{l}\text { Confirmed target site } \\
\text { duplication }\end{array}$ \\
\hline AT2G16820 & AT2G16830 & Rep_Col & AT2G16832 & Mutator-like & NA & NA & NA \\
\hline AT2TE65230 & AT2G34840 & Exp_Col & NO & DNA/MuDr & $2.8 \mathrm{~kb}$ & $1.8 \mathrm{~kb}$ & ATTG \\
\hline NO & AT4G09143 & Rep_Col & AT4G09146 & LTR/Copia & NA & NA & NA \\
\hline Node & AT5G35810 & Rep_Col & AT5G35820 & LTR/Copia & $6.6 \mathrm{~kb}$ & $1.0 \mathrm{~kb}$ & ATACCT \\
\hline NO & AT5G42640 & Rep_Col & AT5G42645 & LTR/Copia & $7.9 \mathrm{~kb}$ & $3.0 \mathrm{~kb}$ & CCGCA \\
\hline NO & AT4G20480 & Exp_Col & AT4G20490 & LTR/GYPSY & NA & NA & NA \\
\hline AT4G10865 & AT4G10870 & Rep_Col & NO & AT4G10880 is not a TE & NA & NA & NA \\
\hline AT2G01550 & AT2G01560 & Rep_Col & NO & $\begin{array}{l}\text { Non-LTR retrotransposon } \\
\text { (LINE) }\end{array}$ & NA & NA & NA \\
\hline NO & AT3G60560 & Rep_Col & AT3G60565 & LTR/Copia & NA & NA & NA \\
\hline AT5TE82820 & AT5G56920 & Rep_Col & AT5TE82825 & $\begin{array}{l}\text { left:DNA/AtREP10D; right:RC/ } \\
\text { Helitron }\end{array}$ & $3.3 \mathrm{~kb}$ & $2.0 \mathrm{~kb}$ & ATTAAGTAA \\
\hline NO & AT5G56910 & Exp_Col & AT5TE82820 & DNA/RP1-AT & $2.1 \mathrm{~kb}$ & $1.8 \mathrm{~kb}$ & no \\
\hline AT2TE37940 & AT2G20910 & Rep_Col & NO & DNA/MuDR & NA & NA & NA \\
\hline NO & AT1G66300 & Rep_Col & AT1TE81190 & $\mathrm{RC} /$ Helitron & NA & NA & NA \\
\hline
\end{tabular}

NA, not available.

A

Chr5

Locus

Ler sequence

Col genome

Ler scaffold

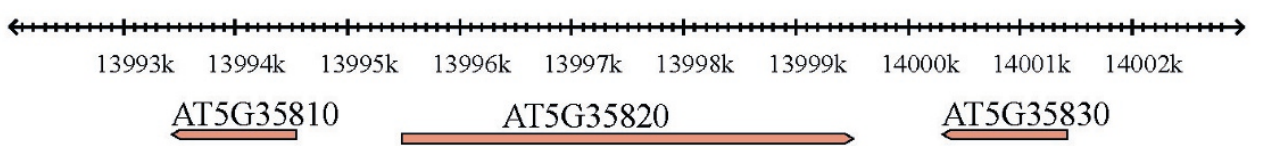

AT5G35810 AT5G35820

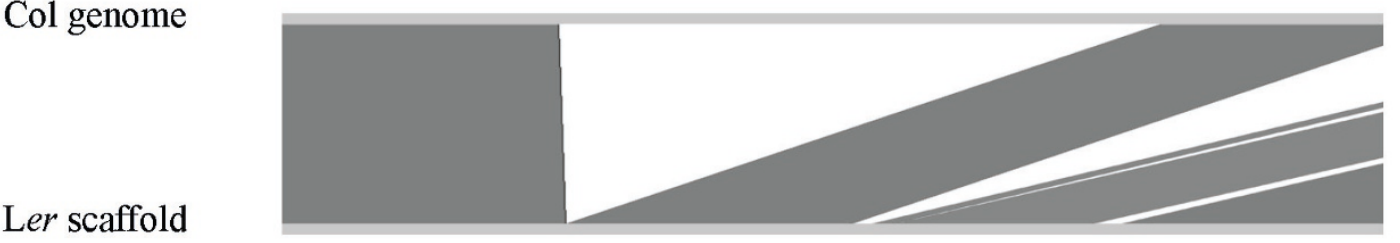

B

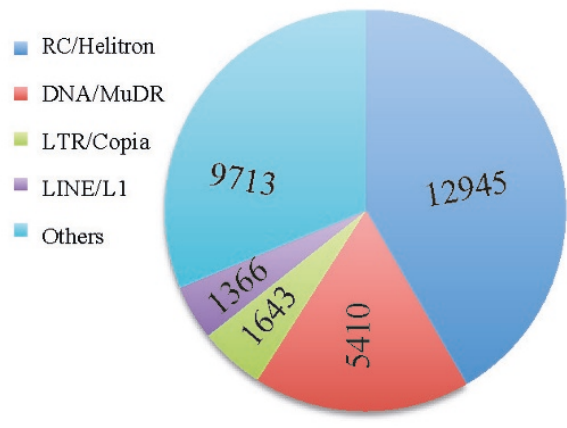

C

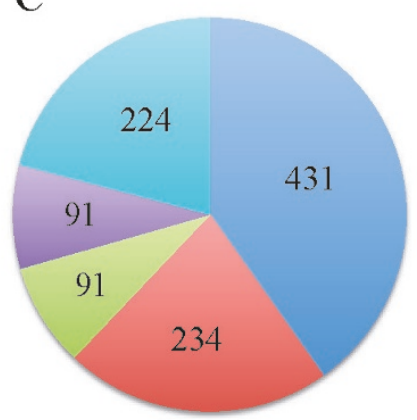

D

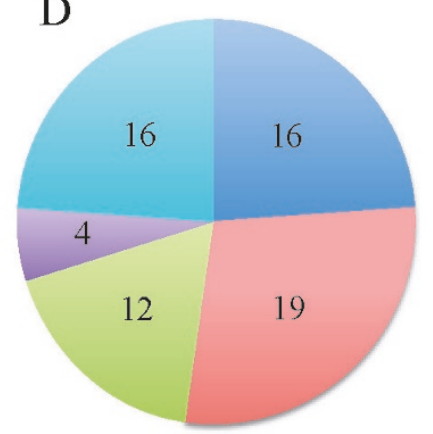

Figure $\mathbf{5}$ Characteristics of TEs present in Col but absent in Ler. (a) TE flanking a Ler-specific H3K27me3 target (AT5G35810) is missing in Ler assembly. The scale shows the sequence coordinates in the Col genome. The red bars show the gene models of AT5G38510, the annotated TE gene AT5G38520 flanking it and the following protein-coding gene AT5G35830. The short gray bars with red frame show sequences present in both genomes according to the sequencing of PCR products; the dashed gray line between short gray bars shows the sequence that is present in Col but missing in Ler. Pictogram below shows sequences that were aligned between the Col genome and Ler scaffold (in gray); white regions could not be aligned. (b) The distribution of different types of TEs in the Col genome. (c) Distribution of different types of TEs that are present in Col but absent in Ler. (d) Distribution of TEs present in Col but absent in Ler and that neighbor H3K9me2 targets. 
Rep_Col set (Table 1). We conclude that in the Arabidopsis accession Col, TEs of the LTR/Copia family have a strong ability to spread their H3K9me2. Interestingly, the family also showed most differential insertions in $\mathrm{Col}$ as compared to Ler, indicating that transposition history and heterochromatic spreading could be correlated (Figure 5a,b).

\section{H3K27me3 is stably inherited in reciprocal F1 hybrids in an allele-specific manner}

Heterochromatin spreading is thought to depend, at least partially, on the recruitment of chromatin modifying complexes by siRNAs and the count of siRNAs was increased in the flanking regions of Rep_Col genes (Figure 3f). In the current model, the action of siRNAs is thought to occur in cis and trans, which could lead to a loss of the H3K27me3 mark from the Ler allele in F1 hybrids, if these siRNAs were provided by the Col allele. We performed H3K27me3 profiling using the ChIP-Seq technique in the $\mathrm{F} 1$ generation of reciprocal hybrids between $\mathrm{Col}$ and $\mathrm{Ler}\left(\mathrm{Col} \times \mathrm{Ler}\right.$ and $\mathrm{Ler} \times \mathrm{Col}$, $+\times 0^{\prime \prime}$, respectively). The sequencing reads were mapped to the TAIR9 reference genome, permitting a mismatch of 3 to allow for small nucleotide polymorphisms in Ler. We used reads from sonicated, non-precipitated chromatin as background to identify 6,648 and $6,170 \mathrm{H} 3 \mathrm{~K} 27 \mathrm{me} 3$ targets in the F1 of Col $\times$ Ler and Ler $\times$ Col, respectively (Additional file 2). These showed an overlap of 5,586 targets (Figure 6a). Of 6,370 H3K27me3 targets in Col, 5,420 were also detected in the $\mathrm{F} 1$ of $\mathrm{Col} \times \mathrm{Ler}$ (Figure 6b). The overlap is similar to that observed between different ChIP-chip data sets and in the range of the expected false discovery rate.

Of the Ler-specific H3K27me3 target genes, approximately half were still positive in both F1. To test whether the loss of H3K27me3 in the hybrids was due to trans regulation or an artifact caused by the expected reduced number of reads if those were generated by a single H3K27me3 positive allele, we chose four genes to verify their H3K27me3 state in F1 by ChIP-PCR. All tested loci were still H3K27me3 positive in both F1 groups (Figure 6c).

Targets that were detected as positive in the F1 ChIPseq dataset allowed us to calculate the allele frequency using known SNPs between Col and Ler [32]. In both F1 hybrids, the median allele frequency for Ler-specific H3K27me3 targets is 0 for the Col allele, but 0.5 for common targets (Figure 6c). The allele frequencies of random samples from common targets were significantly different from those observed for Ler-specific H3K27me3 targets (Permutation test, $P<0.001)$. In conclusion, the H3K27me3 mark showed clear allele-specificity in reciprocal hybrids and heterochromatic invasion in trans was not observed.

\section{Discussion}

The distribution of $\mathrm{H} 3 \mathrm{~K} 27 \mathrm{me} 3$ target regions is almost invariant between Col and Ler

Previous studies established that throughout development, the presence of H3K27me3 represents the default state for the majority of targets since only a small number of genes are differentially modified in different tissues and during the embryo-to-seedling transition $[29,44]$. In the developmental context, the loss of H3K27me3 in particular developmental stages or tissues is usually correlated with an increased expression of targets. Several thousands of genes show variable gene expression between different accessions of $A$. thaliana $[45,46]$. It was previously speculated that $\mathrm{H} 3 \mathrm{~K} 27 \mathrm{me} 3$ played a role in allele-specific expression since, in F1 hybrids, differentially trans-regulated genes were depleted in H3K27me3 targets, whereas cis-regulated genes were slightly enriched [46]. The last trend was even more strongly observed in intraspecifc F1 hybrids between A. thaliana and Arabidopsis lyrata, but only for genes that were more highly expressed from the A. lyrata allele [47]. Our study established that most $\mathrm{H} 3 \mathrm{~K} 27$ me3 targets are shared between seedlings of Col and Ler and that the small number of differential H3K27me3 targets cannot mechanistically explain global expression differences between accessions. A possible caveat of this conclusion is that subtle differences in H3K27me3 levels at shared targets may not be resolved by the ChIP-chip method employed and have therefore escaped our attention.

Our data are consistent with a previous study in which H3K27me3 targets were compared between the accessions CVI, C24 and Col [28]. However, the methods to identify differential targets differed between the studies, leading to a considerably higher number of differential H3K27me3 targets identified in the CVI, C24 and Col comparison. As the study by Moghaddam et al. [28] did not include a statistical test to evaluate differential targets, it is likely to have generated a considerable number of false positives. In contrast, our stringent remapping of microarray probes to both the Col genome and the Ler assembly could result in an underestimation of differential targets as highly polymorphic and very similar duplicated regions were excluded from the potential target list (Additional file 3). In particular, this exclusion could be the reason of our failure to detect genuine Col-specific H3K27me3 target regions. The 32 Ler-specific H3K27me3 targets therefore represent a high confidence gene set that allowed us to pinpoint structural features that could explain the observed epigenetic differences.

\section{Cis-effect of $\mathrm{H} 3 \mathrm{~K} 27 \mathrm{me} 3$ inheritance in reciprocal hybrids of Col and Ler}

It is not entirely clear by which mechanisms PcG-complexes are recruited to their target sites, although there 


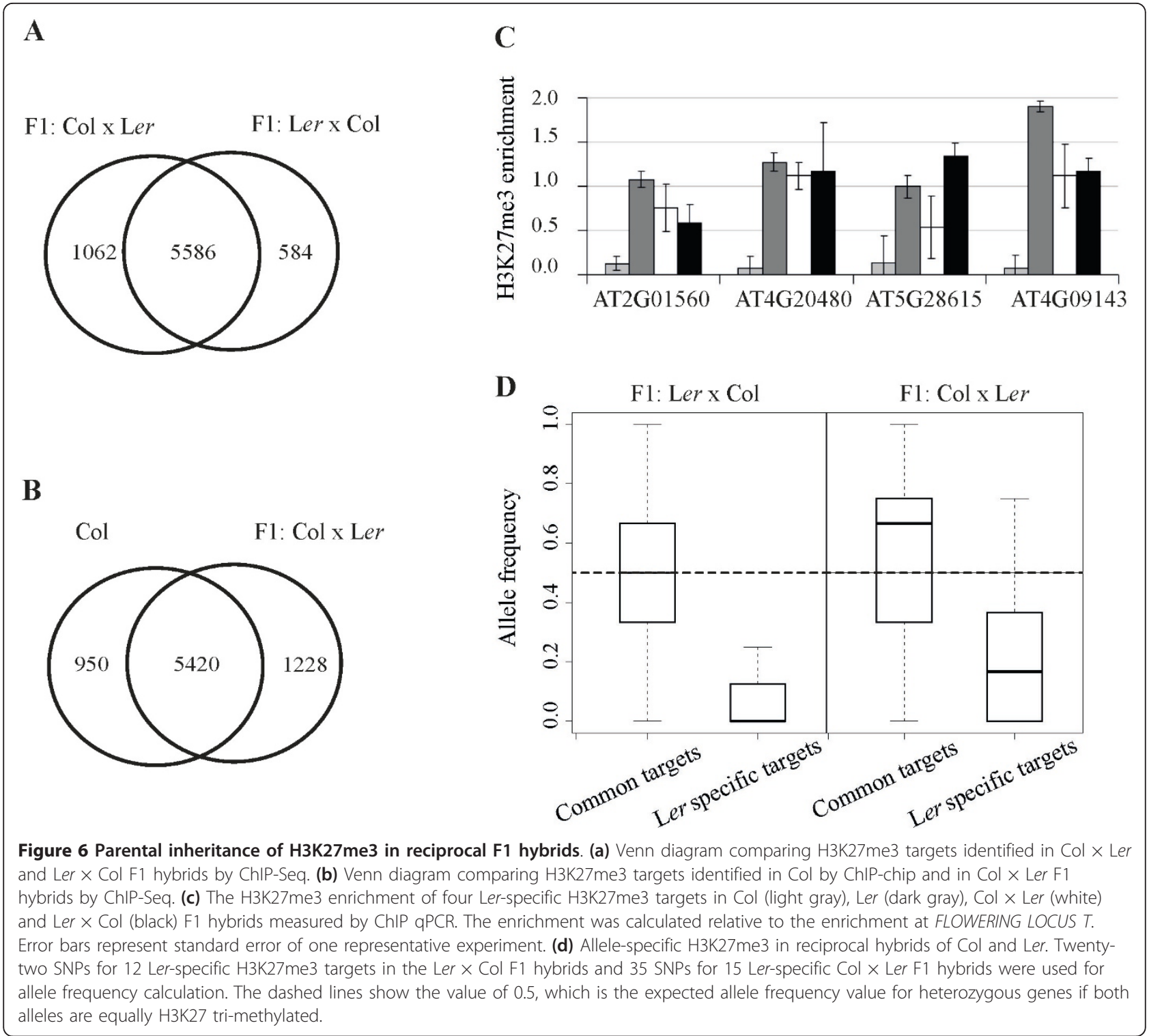

is mounting evidence that longer non-coding RNA transcripts are involved $[24,48]$. Such RNAs could act in trans to recruit H3K27me3. Ler-specific H3K27me3 targets contained no clear candidates of de novo recruitment of H3K27me3, which made it unlikely that H3K27me3 would be recruited to the Col allele in F1 hybrids. siRNAs generated by TEs flanking Ler-specific H3K27me3 targets could also act in trans to initiate heterochromatin formation at the Ler allele in F1 hybrids. Such a process could lead to the generation of stable epialleles. Our ChIP-seq data excluded any possibility of trans-acting effectors, since the inheritance of H3K27me3 was strictly allelic. This is consistent with a previous study that compared histone methylation patterns in hybrids between rice cultivars [49].

\section{Expression of Ler-specific H3K27me3 targets is} consistent with their chromatin states

Although the expectation was that the loss of the repressive H3K27me3 mark correlated with a gain in expression, only the small set of Exp_Col genes substantiated this expectation. The larger Rep_Col gene set was neither expressed in a variety of tissues in Col nor in the seedling stage of 18 additional Arabidopsis accessions (Figure 2).

The expression pattern of Ler-specific H3K27me3 targets can be explained through an analysis of available chromatin modification data in Col. Based on a global analysis of 12 chromatin modifications, Roudier et al. [18] defined four chromatin states, CS1 to CS4, of which CS1 is associated with active expression of genes, whereas CS2 to CS4 are condensed chromatin states with little or no 
gene expression [18]. CS1 is characterized by the active histone modifications H3K4me3, H3K36me3 and H3K9me3, the latter a euchromatic mark in Arabidopsis but heterochromatic in animals. CS2 is defined by the repressive mark $\mathrm{H} 3 \mathrm{~K} 27 \mathrm{me} 3$ and CS3 by the silencing mark $\mathrm{H} 3 \mathrm{~K} 9 \mathrm{me} 2$ as well as increased DNA methylation. CS4 is ill defined by chromatin modifications as none of the 12 marks seems enriched. While common H3K27me3 targets were clearly CS2, we found the CS1 attribute H3K4me3 enriched at Exp_Col genes, whereas CS3 marks were enriched at Rep_Col genes (Figure 3).

\section{Chromatin changes leading to differential H3K27me3 targeting}

In the expression comparison between seedlings of different accessions, all Exp_Col genes were at their lowest expression state in Ler, but showed only occasional absence of expression among the remaining 17 accessions. For two Exp_Col genes, AT3G60150 and AT2G34840, H3K27me3 invasion from flanking regions could explain the gene-specific H3K27me3 enrichment in Ler.

For most Rep_Col genes, H3K9me2 seems to be the derived state based on the following observations. The presence of siRNA signatures at the flanks rather than bodies of Rep_Col genes indicated that heterochromatic regions in the vicinity of Rep_Col genes play a functional role in the change from CS2 to CS3 chromatin. In Col, Rep_Col genes were frequently flanked by TEs, which could generate these siRNAs, but this feature did not distinguish Rep_Col genes from H3K27me3 targets in general (Figure 4). However, in several cases, flanking TEs were missing in Ler, suggesting that their insertion in Col changed the chromatin from CS2 to CS3 (Figure 5; Figure S3 in Additional file 1). In several cases, analysis of target site duplications supports the insertion of the TE in Col as opposed to an excision in Ler. It seems likely that siRNAs produced by, or targeted to, the inserted TEs recruit heterochromatic modifications such as DNA methylation and subsequently $\mathrm{H} 3 \mathrm{~K} 9 \mathrm{me} 2$, which then spread into the adjoining H3K27me3 target gene. Since the CS2 and CS3 chromatin is mutually exclusive, such heterochromatin invasion would lead to a loss of H3K27me3 [18,25].

It is unclear why the Rep_Col genes were invaded by heterochromatin whereas, in general, H3K27me3 target genes appear to form a barrier to heterochromatin spreading given the enrichment of TEs in their neighborhood (Figure 4). Two scenarios may explain these observations. First, particular families/classes of flanking TEs could be more invasive than others and thus particularly enriched in the vicinity of Rep_Col genes. In mammals, a different tendency of TEs to spread H3K9me3 to nearby regions has been described [50]. Indeed, we found an over-representation of heterochromatic protein-coding genes in the vicinity of LTR/Copia TEs that are polymorphic between
Col and Ler (Figure 5). Absence of selection could be a second scenario to explain heterochromatic spreading only for a small subset of TE-flanked H3K27me3 targets. If expression of Rep_Col genes is not required under any circumstances neither in Col nor Ler, complete silencing by the heterochromatin pathway instead of repression by the PcG pathway has no consequences for the plants. Interestingly, in two cases the Exp_Col genes flanked heterochromatic TEs that were absent in Ler (Table 1). Possibly, in these situations high expression and the corresponding CS1 chromatin have evolved to form a strong barrier against invasive heterochromatin. Schmitges et al. [11] proposed that H3K4me3 acts as a barrier for the deposition of H3K27me3, and this could apply to repressive marks in general. CS1 chromatin could have been selected for because residual expression of these Exp_Col genes gave a fitness advantage, but their role could also be more passive to provide a functional chromatin barrier because adjacent genes were important for plant survival. Alternatively, it may have been the TE insertions per se that caused activation of a flanking target. It has been shown in maize and rice that transposon insertions can have positive effects on gene expression through disruption of native promoter regulation or introduction of new regulatory elements [51,52].

Although polymorphic TEs may explain the majority of Ler-specific H3K27me3 targets, there are some limitations. Ler-specific H3K27me3 targets are not always flanked by TEs and the corresponding TEs are not always missing in Ler, indicating that polymorphic TEs are not the only cause of variation in H3K27me3. Possibly, in at least some cases serendipitous recruitment of H3K27me3 in one and H3K9me2 in the other accession to genes not expressed in either accession resulted in differential labeling.

\section{Conclusions}

Intraspecific variation in $\mathrm{H} 3 \mathrm{~K} 27 \mathrm{me} 3$ is rare and an unlikely cause for differential expression between accessions. A small, high-confidence set of Ler-specific H3K27me3 targets allowed pinpointing structural features that explain intraspecific variation for this epigenetic mark. Insertion of TEs at the flanks of target genes seems the major cause of H3K27me3 loss through heterochromatic invasion. In particular, retrotransposons of the LTR/Copia class were linked to H3K9me2-marked protein coding gene loci, indicating that these TEs were particularly aggressive towards their neighbors.

\section{Materials and methods}

\section{Plant material and growth conditions}

A. thaliana accessions $\mathrm{Col}$ and Ler and their hybrids were grown under long-day conditions (16 hours light, 8 hours dark) for 10 or 11 days at $20^{\circ} \mathrm{C}$ on Murashige and Skoog medium supplemented with $1 \%$ sucrose after 
stratification at $4^{\circ} \mathrm{C}$ for 2 to 4 days to synchronize germination. Light was provided by fluorescent tubes. For intraspecific crossing, Col and Ler plants were grown on soil under long-day conditions. Five flower buds on the primary shoot and two side shoots were emasculated and manually cross-pollinated, while all other flower buds were removed. The seeds of each genotype were pooled and the success rate of the crosses was determined by PCR using primers that detected an insertion between Ler and Col (forward, 5'-CTGGAGATCATCCAACAAAGG-3'; reverse, 5'-GGCAATGGAATGGGC TGGTC-3'). Seed pools with less than $10 \%$ maternal contamination were used in the F1 hybrid studies.

\section{ChIP experiments}

ChIP experiments were performed as described [53] except that chromatin was sonicated with a BioRuptor from Diagenode (Liège, Belgium) for 10 times 30s at high setting with $60 \mathrm{~s}$ intermittent cooling in ice-water. A DNA fragment size of 300 to 1,000 bp was controlled by running an aliquot of de-crosslinked and purified DNA on $1.5 \%$ agarose gels. The following antibodies were used in immunoprecipitations: anti-rat IgG (R9255, Sigma; St. Louis, MO, USA), anti-H3K27me3 (07-449, lot number DAM 1662421, Millipore; Temecula, CA, USA), and antiH3K9me2 (pAB-060-050, lot number 90-0041, Diagenode; Liège, Belgium). Specificity of antibodies was found to vary between lots and was therefore confirmed for each new lot by western blot against a dilution series of modified peptides (Figure S5A in Additional file 1). Furthermore, crosshybridization of H3K27me3 antibodies with H3K27me1 signal was excluded by probing Ler-specific H3K27me3 targets with antibodies specific for H3K27me1 (pAB-045050, lot number A116-00342, Diagenode; Liège, Belgium) (Figure S5B in Additional file 1). A very low signal was detected in anti-rat IgG-antibody precipitations and was subtracted as background. qPCR data are shown as fold enrichment of the input, or fold enrichment of input and compared to the fold enrichment of the input for the FLOWERING LOCUS T gene as indicated; the error bars represent standard error of three technical replicates. At least two independent biological replicates were performed for each experiment and a representative one is shown. Primers used for qPCR are described in Table S5 in Additional file 1.

\section{ChIP-chip and ChIP-Seq experiments}

ChIP-chip experiments were carried out as described elsewhere using 10- or 11-day-old seedlings harvested at ZT16 [53]. DNA samples were amplified using a linkermediated PCR and hybridized to two-color microarrays from Roche-NimbleGen (Madison, WI, USA); input samples were hybridized as reference. Two biological replicates were hybridized per accession. For ChIP-Seq, $80 \%$ of a ChIP experiment precipitated with H3K27me3 antibodies was used to prepare libraries using the ChIP-Seq library preparation kit from Illumina (number 11257047) according to the manufacturer's instructions. Each library was loaded on two lanes of the Illumina Genome Analyzers IIx to obtain single end 34-mer reads. The sonicated input of a chromatin sample from Col was used as background reference and loaded only on one lane for sequencing.

\section{ChIP-chip data analysis}

ChIP-chip data were analyzed using the custom R package ChIPR [31] that integrates the RINGO package [54]. Probes were remapped to the $\mathrm{Col}$ and Ler genomes using BWA 0.5.9 [55] allowing maximal two mismatches. To predict $\mathrm{H} 3 \mathrm{~K} 27 \mathrm{me} 3$ targets in $\mathrm{Col}$ and Ler, only probes uniquely mapped to the Col TAIR9 genome with an edit distance of two nucleotides to the second best matching site were used. This step removed probes that were likely to hybridize to more than one region. A descriptive ndffile was created that contained only the reannotated probes. Following the ChIPR pipeline, loess normalization was applied within arrays then the normalization method 'scale' was used between arrays to remove inconsistencies. Positive probes were identified by the method implemented in RINGO and all positive probes separated by gaps smaller than 300 bp were combined into ChIP-enriched regions. Genes covered by these regions for at least $30 \%$ of their gene body and at least 300 bp or minimally $1,000 \mathrm{bp}$ (for very long genes) were defined as H3K27me3 targets.

To predict differentially H3K 27 me 3 enriched genes between the accessions, only probes uniquely mapped to the Col genome and the published Ler scaffolds were used. For each annotated gene in TAIR9, a median value was determined per replicate and accession based on all probes that covered the gene body. Genes with less than three uniquely mapped probes or less than $40 \%$ coverage by probes were removed from the analysis. Genes that were not H3K27me3 targets in the global target analysis of either genome were also excluded to ensure that the Coland Ler-specific H3K27me3 targets have high H3K27me3 signal at least in one accession (Table S3 in Additional file 1). The R package RankProd [56] was used to define the most differentially labeled genes between Col and Ler. Genes significant at a proportion of false predictions (pfp) smaller than 0.15 were regarded as differentially enriched in one accession.

\section{ChIP-Seq data analysis}

Reads from two Illumina GAIIx lanes for each sample were merged and mapped to the $\mathrm{Col}$ reference genome (TAIR9) using BWA 0.5.9 [55]. The maximal edit distance was three including a maximal gap of one. Low quality sequences at read ends were trimmed with BWA 
while mapping. Reads mapping to the genome were sorted according to the Col TAIR9 genome coordinates using SAMtools. [55]. Reads mapped to identical positions in the genome were cleaned with Picard MarkDuplicates [57] by keeping one copy to avoid PCR artifacts. $\mathrm{H} 3 \mathrm{~K} 27 \mathrm{me} 3$ enriched targets in the $\mathrm{F} 1$ generation of $\mathrm{Col} \times \mathrm{Ler}$ and Ler $\times$ Col were predicted with SICER V1.03 using the chromatin input from Col as background [58]. Only uniquely mapped reads were used for prediction of peaks. Peaks separated by gaps smaller than 200 bp were merged. In hybrids, genes with at least $20 \%$ and $200 \mathrm{bp}$, or $800 \mathrm{bp}$ (for very long genes) covered by peaks were defined as H3K27me3 targets. A short reads pileup format file was generated by SAMtools based on the non-redundant reads. This file shows which and how many reads pile up at genomic coordinates. The pileup file was used for detection of allele-specific enrichment for H3K27me3. SNP data between $\mathrm{Col}$ and Ler were downloaded from the 1001 Genome Project [39]. The allele frequencies of Ler-specific and common H3K27me3 targets were calculated based on the SNP data and the short reads pileup format file. SNP positions with less than three uniquely mapped reads were excluded. Reads that were not the same as the reference Col nor the Ler allele at SNP positions were also excluded. To test whether there is a high probability to observe the allele frequency of Ler-specific targets also in the common H3K27me3 target list, the same number of SNPs as analyzed in the Ler-specific targets were drawn from all SNPs in H3K27me3 targets for 100,000 times. The allele frequency was calculated for each randomization. This resulted in a $P$-value $<0.00001$ being calculated for both reciprocal hybrids.

\section{Sequence comparison between Col and Ler}

The Arabidopsis Col genome (TAIR9) was used as reference genome. Ler genome data were obtained from the 1001 Genomes data center [59]. The whole genome alignment tool MUMmer was used to align all scaffolds of Ler to the Col reference sequence. The alignment was performed following the instructions for 'Mapping a draft sequence to a finished sequence' [60]. The parameter setting used was 'nucmer -mum -b 1000 -1 35 -c $80-\mathrm{f}$-prefix $=$ outputFolder referenceSquence LerassemblySequence'. With such a setting, first only anchors that were unique in both reference and query were allowed for alignment. nucmer further extended alignments across high diversity regions until reaching maximally 1,000 edit distance. If the diverged regions or indels are larger than 1,000 bp, the alignment will break. Finally we restricted the alignment to match the forward strand of the query.

To check whether the transposable elements flanking Ler-specific H3K27me3 target genes in the Col genome exist also in the Ler genome, the respective sequences of gene bodies and their up/downstream regions were extracted from both genomes using a custom $\mathrm{R}$ script and aligned again with MUMmer. The sequences and the alignment result visualized with Artemis Comparison Tool [61] for one example gene are shown in Figure 5.

The detected deletion of transposable elements was further tested for five Ler-specific H3K27me3 loci by sequencing PCR products spanning the respective region. Genomic DNA from Col and Ler was used as template (PCR primer list in Table S5 in Additional file 1). PCR was performed using Phusion Taq (M0530 S; NewEngland BioLabs (Ipswich, MA, USA)) with the high fidelity buffer. PCR product size was determined on $1 \%$ agarose gels. PCR products were either purified by polyethylene glycol precipitation or directly from the gel using a GelExtraction Kit (Machery-Nagl Düren, Germany) before Sanger sequencing. Sequences obtained from Ler were aligned to the Col genome (TAIR10) using BLAST.

\section{Expression analysis}

Whole seedlings grown on plates were harvested for total RNA extraction at day 7,10 and 12. The aerial part of soil-grown plants was collected on day 13 and 20 and tissue-specific samples (rosette and cauline leaves, stem, open flower, apex enriched tissue and silique) were obtained at days 27 and 34 to extract total RNA with the RNeasy Mini kit (Qiagen, Hilden, Germany). Five micrograms of RNA was DNaseI treated using the DNA-free kit (Ambion Austin, TX, USA) prior to cDNA synthesis with SuperScript II Reverse Transcriptase (18064-014, Invitrogen Carlsbad, CA, USA). Quantitative reverse-transcribed (qRT)-PCR was performed using a Roche LightCycler (Mannheim, Germany) and EVA Green dye detection (Biotium, Hayward, CA). PP2A (AT1G13320) was used as reference gene. Primers are listed in Table S5 in Additional file 1 .

\section{Primary accession}

ChIP-chip and ChIP-Seq data reported in the manuscript are available at ArrayExpress under series accession number E-MTAB-749 (in accordance with MIAME guidelines) and E-MTAB-1043, respectively.

\section{Additional material}

Additional file 1: Supplementary Figures S1 to S5, Tables S3 to S5 and Supplemental Methods.

Additional file 2: Table S1. Supplemental Table 1. H3K27me3 target gene list of Col, Ler, F1 hybrids Col x Ler and Ler x Col.

Additional file 3: Table S2. Supplemental Table 2. Genes that were removed from the analysis after stringent remapping of probes to $\mathrm{Col}$ and Ler scaffolds. 


\section{Abbreviations}

Bp: base pair; ChIP: chromatin immunoprecipitation; ChIP-chip: chromatin immunoprecipitation followed by microarray hybridization; ChIP-PCR: chromatin immunoprecipitation followed by PCR; ChIP-seq: chromatin immunoprecipitation followed by high throughput sequencing; Col: Columbia; HMT: histone methyl-transferase; CS: chromatin state; H3K4me3: histone $\mathrm{H3}$ tri-methylated at lysine 4; $\mathrm{H} 3 \mathrm{~K} 9 \mathrm{me2}$ : histone $\mathrm{H} 3$ di-methylated at lysine 9; H3K27me3: histone H3 tri-methylated at lysine 27; Ler: Landsberg erecta; PCG, Polycomb group; PCR: polymerase chain reaction; PRC: Polycomb repressive complex; qPCR: quantitative PCR; qRT-PCR: quantitative reverse-transcribed PCR; siRNA: small interfering RNA; SNP: single nucleotide polymorphism; TAIR: The Arabidopsis Information Resources; TE: transposable element.

\section{Authors' contributions}

$J R$ performed the experiments, XD analyzed the data, and both evaluated and interpreted the data. UG, JE and FH made important suggestions to improve the analysis and interpretation of data. FT conceived the study; HS and FT coordinated the research. XD, JR, HS and FT wrote the manuscript. All authors read and approved the final manuscript.

\section{Acknowledgements}

We thank the ERA-NET Plant Genomics (Deutsche Forschungsgemeinschaft (DFG)) for funding the PCG-code project; the Max Planck Society for complementary funding.

\section{Author details}

${ }^{1}$ Max Planck Institute for Plant Breeding Research, Carl von Linne Weg 10, 50829 Köln, Germany. ${ }^{2}$ Current address: Institute for Evolution and Biodiversity, University of Münster, Hüfferstr. 1, 48149 Münster, Germany. ${ }^{3}$ Current address: University of Bonn, Institute of Crop Science and Resource Conservation, Crop Bioinformatics, Katzenburgweg 2, 53115 Bonn, Germany.

Received: 1 August 2012 Revised: 13 November 2012

Accepted: 19 December 2012 Published: 19 December 2012

\section{References}

1. Sawarkar R, Paro R: Interpretation of developmental signaling at chromatin: the Polycomb perspective. Dev Cell 2010, 19:651-661.

2. Mohn F, Schubeler D: Genetics and epigenetics: stability and plasticity during cellular differentiation. Trends Genet 2009, 25:129-136.

3. Beisel C, Paro R: Silencing chromatin: comparing modes and mechanisms. Nat Rev Genet 2011, 12:123-135.

4. Schotta G, Ebert A, Krauss V, Fischer A, Hoffmann J, Rea S, Jenuwein T, Dorn R, Reuter G: Central role of Drosophila SU(VAR)3-9 in histone H3-K9 methylation and heterochromatic gene silencing. EMBO J 2002, 21:1121-1131

5. Fischer A, Hofmann I, Naumann K, Reuter G: Heterochromatin proteins and the control of heterochromatic gene silencing in Arabidopsis. J Plant Physiol 2006, 163:358-368.

6. Stam M, Mittelsten Scheid O: Paramutation: an encounter leaving a lasting impression. Trends Plant Sci 2005, 10:283-290.

7. Farrona S, Coupland G, Turck F: The impact of chromatin regulation on the floral transition. Semin Cell Dev Biol 2008, 19:560-573.

8. Krishnan S, Horowitz S, Trievel RC: Structure and function of histone H3 lysine 9 methyltransferases and demethylases. Chembiochem 2011, 12:254-263.

9. Cosgrove MS, Wolberger C: How does the histone code work? Biochem Cell Biol 2005, 83:468-476

10. Irvine DV, Zaratiegui M, Tolia NH, Goto DB, Chitwood DH, Vaughn MW, Joshua-Tor L, Martienssen RA: Argonaute slicing is required for heterochromatic silencing and spreading. Science 2006, 313:1134-1137.

11. Schmitges FW, Prusty AB, Faty M, Stutzer A, Lingaraju GM, Aiwazian J, Sack R, Hess D, Li L, Zhou S, Bunker RD, Wirth U, Bouwmeester T, Bauer A Ly-Hartig N, Zhao K, Chan H, Gu J, Gut H, Fischle W, Muller J, Thoma NH: Histone methylation by PRC2 is inhibited by active chromatin marks. Mol Cell 2011, 42:330-341.

12. Margueron R, Justin N, Ohno K, Sharpe ML, Son J, Drury WJ, Voigt $P$, Martin SR, Taylor WR, De Marco V, Pirrotta V, Reinberg D, Gamblin SJ: Role of the polycomb protein EED in the propagation of repressive histone marks. Nature 2009, 461:762-767.
13. Simon SA, Meyers BC: Small RNA-mediated epigenetic modifications in plants. Curr Opin Plant Biol 2011, 14:148-155.

14. Lindroth AM, Shultis D, Jasencakova Z, Fuchs J, Johnson L, Schubert D, Patnaik D, Pradhan S, Goodrich J, Schubert I, Jenuwein T, Khorasanizadeh S, Jacobsen SE: Dual histone H3 methylation marks at lysines 9 and 27 required for interaction with CHROMOMETHYLASE3. EMBO J 2004, 23:4286-4296.

15. Lahmy S, Bies-Etheve N, Lagrange T: Plant-specific multisubunit RNA polymerase in gene silencing. Epigenetics 2010, 5:4-8.

16. Ma MK, Heath C, Hair A, West AG: Histone crosstalk directed by H2B ubiquitination is required for chromatin boundary integrity. PLOS Genet 2011, 7:e1002175.

17. Aichinger E, Villar CB, Farrona S, Reyes JC, Hennig L, Kohler C: CHD3 proteins and polycomb group proteins antagonistically determine cell identity in Arabidopsis. PLoS Genet 2009, 5:e1000605.

18. Roudier F, Ahmed I, Berard C, Sarazin A, Mary-Huard T, Cortijo S, Bouyer D, Caillieux E, Duvernois-Berthet E, Al-Shikhley L, Giraut L, Despres B, Drevensek S, Barneche F, Derozier S, Brunaud V, Aubourg S, Schnittger A, Bowler C, Martin-Magniette ML, Robin S, Caboche M, Colot V: Integrative epigenomic mapping defines four main chromatin states in Arabidopsis. EMBO J 2011, 30:1928-1938

19. Bratzel F, Lopez-Torrejon G, Koch M, Del Pozo JC, Calonje M: Keeping cell identity in Arabidopsis requires PRC1 RING-finger homologs that catalyze H2A monoubiquitination. Curr Biol 2010, 20:1853-1859.

20. Chen D, Molitor A, Liu C, Shen WH: The Arabidopsis PRC1-like ring-finger proteins are necessary for repression of embryonic traits during vegetative growth. Cell Res 2010, 20:1332-1344.

21. Scheuermann JC, Gutierrez L, Muller J: Histone H2A monoubiquitination and Polycomb repression: The missing pieces of the puzzle. Fly (Austin) 2012, 6 .

22. Gindhart JG Jr, Kaufman TC: Identification of Polycomb and trithorax group responsive elements in the regulatory region of the Drosophila homeotic gene Sex combs reduced. Genetics 1995, 139:797-814.

23. Rinn JL, Kertesz M, Wang JK, Squazzo SL, Xu X, Brugmann SA Goodnough LH, Helms JA, Farnham PJ, Segal E, Chang HY: Functional demarcation of active and silent chromatin domains in human HOX loci by noncoding RNAs. Cell 2007, 129:1311-1323.

24. Heo JB, Sung S: Vernalization-mediated epigenetic silencing by a long intronic noncoding RNA. Science 2011, 331:76-79.

25. Turck F, Roudier F, Farrona S, Martin-Magniette ML, Guillaume E, Buisine N, Gagnot S, Martienssen RA, Coupland G, Colot V: Arabidopsis TFL2/LHP1 specifically associates with genes marked by trimethylation of histone H3 lysine 27. PLoS Genet 2007, 3:e86.

26. Zhang X, Clarenz O, Cokus S, Bernatavichute YV, Pellegrini M, Goodrich J, Jacobsen SE: Whole-genome analysis of histone H3 lysine 27 trimethylation in Arabidopsis. PLoS Biol 2007, 5:e129.

27. Oh S, Park S, van Nocker S: Genic and global functions for Paf1C in chromatin modification and gene expression in Arabidopsis. PLOS Genet 2008, 4:e1000077.

28. Moghaddam AM, Roudier F, Seifert M, Berard C, Magniette ML, Ashtiyani RK, Houben A, Colot V, Mette MF: Additive inheritance of histone modifications in Arabidopsis thaliana intra-specific hybrids. Plant J 2011, 67:691-700

29. Lafos M, Kroll P, Hohenstatt ML, Thorpe FL, Clarenz O, Schubert D: Dynamic regulation of $\mathrm{H} 3 \mathrm{~K} 27$ trimethylation during Arabidopsis differentiation. PLoS Genet 2011, 7:e1002040.

30. Moazed D, Buhler M, Buker SM, Colmenares SU, Gerace EL, Gerber SA, Hong EJ, Motamedi MR, Verdel A, Villen J, Gygi SP: Studies on the mechanism of RNAi-dependent heterochromatin assembly. Cold Spring Harb Symp Quant Biol 2006, 71:461-471.

31. Gobel U, Reimer J, Turck F: Genome-wide mapping of protein-DNA interaction by chromatin immunoprecipitation and DNA microarray hybridization (ChIP-chip). Part B: ChIP-chip data analysis. Methods Mol Biol 2010, 631:161-184.

32. Schneeberger K, Ossowski S, Ott F, Klein JD, Wang X, Lanz C, Smith LM, Cao J, Fitz J, Warthmann N, Henz SR, Huson DH, Weigel D: Referenceguided assembly of four diverse Arabidopsis thaliana genomes. Proc Natl Acad Sci USA 2011, 108:10249-10254.

33. Weinhofer I, Hehenberger E, Roszak P, Hennig L, Kohler C: H3K27me3 profiling of the endosperm implies exclusion of polycomb group protein targeting by DNA methylation. PLOS Genet 2010, 6:pii:e1001152. 
34. Engelhorn J, Reimer JJ, Leuz I, Gobel U, Huettel B, Farrona S, Turck F: DEVELOPMENT-RELATED PCG TARGET IN THE APEX 4 controls leaf margin architecture in Arabidopsis thaliana. Development 2012, 139:2566-2575.

35. Laubinger S, Zeller G, Henz SR, Sachsenberg T, Widmer CK, Naouar N, Vuylsteke M, Scholkopf B, Ratsch G, Weigel D: At-TAX: a whole genome tiling array resource for developmental expression analysis and transcript identification in Arabidopsis thaliana. Genome Biol 2008, 9:R112.

36. Gan X, Stegle O, Behr J, Steffen JG, Drewe P, Hildebrand KL, Lyngsoe R, Schultheiss SJ, Osborne EJ, Sreedharan VT, Kahles A, Bohnert R, Jean G, Derwent P, Kersey P, Belfield EJ, Harberd NP, Kemen E, Toomajian C, Kover PX, Clark RM, Ratsch G, Mott R: Multiple reference genomes and transcriptomes for Arabidopsis thaliana. Nature 2011, 477:419-423.

37. Haynes KA, Leibovitch BA, Rangwala SH, Craig C, Elgin SC: Analyzing heterochromatin formation using chromosome 4 of Drosophila melanogaster. Cold Spring Harb Symp Quant Biol 2004, 69:267-272.

38. Billon P, Cote J: Precise deposition of histone H2A.Z in chromatin for genome expression and maintenance. Biochim Biophys Acta 2012, 1819:290-302.

39. Mavrich TN, Jiang C, loshikhes IP, Li X, Venters BJ, Zanton SJ, Tomsho LP, Qi J, Glaser RL, Schuster SC, Gilmour DS, Albert I, Pugh BF: Nucleosome organization in the Drosophila genome. Nature 2008, 453:358-362.

40. Creyghton MP, Markoulaki S, Levine SS, Hanna J, Lodato MA, Sha K, Young RA, Jaenisch R, Boyer LA: H2AZ is enriched at polycomb complex target genes in ES cells and is necessary for lineage commitment. Cell 2008, 135:649-661.

41. Zilberman D, Coleman-Derr D, Ballinger T, Henikoff S: Histone H2A.Z and DNA methylation are mutually antagonistic chromatin marks. Nature 2008, 456:125-129

42. Bernatavichute W, Zhang X, Cokus S, Pellegrini M, Jacobsen SE: Genomewide association of histone $\mathrm{H} 3$ lysine nine methylation with CHG DNA methylation in Arabidopsis thaliana. PLoS One 2008, 3:e3156.

43. Zhang X, Yazaki J, Sundaresan A, Cokus S, Chan SW, Chen H, Henderson IR, Shinn P, Pellegrini M, Jacobsen SE, Ecker JR: Genome-wide high-resolution mapping and functional analysis of DNA methylation in arabidopsis. Cell 2006, 126:1189-1201.

44. Bouyer D, Roudier F, Heese M, Andersen ED, Gey D, Nowack MK, Goodrich J, Renou JP, Grini PE, Colot V, Schnittger A: Polycomb repressive complex 2 controls the embryo-to-seedling phase transition. PLoS Genet 2011, 7:e1002014.

45. Kliebenstein DJ, West MA, van Leeuwen H, Kim K, Doerge RW, Michelmore RW, St Clair DA: Genomic survey of gene expression diversity in Arabidopsis thaliana. Genetics 2006, 172:1179-1189.

46. Zhang X, Borevitz JO: Global analysis of allele-specific expression in Arabidopsis thaliana. Genetics 2009, 182:943-954.

47. He F, Zhang X, Hu J, Turck F, Dong X, Goebel U, Borevitz J, de Meaux J: Genome-wide analysis of cis-regulatory divergence between species in the Arabidopsis genus. Mol Biol Evol 2012, 29:3385-3395.

48. Schuettengruber B, Chourrout D, Vervoort M, Leblanc B, Cavalli G: Genome regulation by polycomb and trithorax proteins. Cell 2007, 128:735-745.

49. He G, Zhu X, Elling AA, Chen L, Wang X, Guo L, Liang M, He H, Zhang H, Chen F, Qi Y, Chen R, Deng XW: Global epigenetic and transcriptional trends among two rice subspecies and their reciprocal hybrids. Plant Cell 2010, 22:17-33.

50. Rebollo R, Karimi MM, Bilenky M, Gagnier L, Miceli-Royer K, Zhang Y, Goyal P, Keane TM, Jones S, Hirst M, Lorincz MC, Mager DL: Retrotransposon-induced heterochromatin spreading in the mouse revealed by insertional polymorphisms. PLOS Genet 2011, 7:e1002301

51. Pooma W, Gersos C, Grotewold E: Transposon insertions in the promoter of the Zea mays a1 gene differentially affect transcription by the Myb factors $P$ and C1. Genetics 2002, 161:793-801.

52. Huang X, Lu G, Zhao Q, Liu X, Han B: Genome-wide analysis of transposon insertion polymorphisms reveals intraspecific variation in cultivated rice. Plant Physiol 2008, 148:25-40.

53. Reimer JJ, Turck F: Genome-wide mapping of protein-DNA interaction by chromatin immunoprecipitation and DNA microarray hybridization (ChIP-chip). Part A: ChIP-chip molecular methods. Methods Mol Biol 2010, 631:139-160

54. Toedling J, Skylar O, Krueger T, Fischer JJ, Sperling S, Huber W: Ringo-an R/ Bioconductor package for analyzing ChIP-chip readouts. BMC Bioinformatics 2007, 8:221.
55. Li H, Handsaker B, Wysoker A, Fennell T, Ruan J, Homer N, Marth G, Abecasis G, Durbin R: The Sequence Alignment/Map format and SAMtools. Bioinformatics 2009, 25:2078-2079.

56. Hong F, Breitling R, McEntee CW, Wittner BS, Nemhauser JL, Chory J: RankProd: a bioconductor package for detecting differentially expressed genes in meta-analysis. Bioinformatics 2006, 22:2825-2827.

57. Picard.. [http://picard.sourceforge.net].

58. Zang C, Schones DE, Zeng C, Cui K, Zhao K, Peng W: A clustering approach for identification of enriched domains from histone modification ChIP-Seq data. Bioinformatics 2009, 25:1952-1958.

59. 1001 Genomes: Ler genome data.. [http://1001genomes.org/data/MPI/ MPISchneeberger2010/releases/2010_09_30/].

60. MUMmer: Mapping a draft sequence to a finished sequence.. [http:// mummer.sourceforge.net/manual/\#mappingdraft].

61. Carver TJ, Rutherford KM, Berriman M, Rajandream MA, Barrell BG, Parkhill J: ACT: the Artemis Comparison Tool. Bioinformatics 2005, 21:3422-3423.

62. Backman TW, Sullivan CM, Cumbie JS, Miller ZA, Chapman EJ, Fahlgren N, Givan SA, Carrington JC, Kasschau KD: Update of ASRP: the Arabidopsis Small RNA Project database. Nucleic Acids Res 2008, 36:D982-985.

doi:10.1186/gb-2012-13-12-r117

Cite this article as: Dong et al: Natural variation of H3K27me3 distribution between two Arabidopsis accessions and its association with flanking transposable elements. Genome Biology 2012 13:R117.

\section{Submit your next manuscript to BioMed Central and take full advantage of:}

- Convenient online submission

- Thorough peer review

- No space constraints or color figure charges

- Immediate publication on acceptance

- Inclusion in PubMed, CAS, Scopus and Google Scholar

- Research which is freely available for redistribution 